\title{
Model of HIV-1 Disease Progression Based on Virus-Induced Lymph Node Homing and Homing-Induced Apoptosis of CD4 ${ }^{+}$Lymphocytes
}

\author{
*Denise Kirschner, $\dagger$ G. F. Webb, and $\ddagger$ Miles Cloyd \\ *Department of Microbiology and Immunology, The University of Michigan Medical School, Ann Arbor, Michigan; †Department \\ of Mathematics, Vanderbilt University, Nashville, Tennessee; and $¥$ Department of Microbiology and Immunology, The University \\ of Texas Medical Branch, Galveston, Texas, U.S.A.
}

\begin{abstract}
Summary: Several proposed theories have described the progression of HIV infection. Even so, no concrete evidence supports any as comprehensive, including, for example, why the CD4 ${ }^{+}$T-cell counts fall from $1000 / \mathrm{mm}^{3}$ of blood to roughly $100 / \mathrm{mm}^{3}$ over an average 10 -year period, whereas concomitant viral loads are relatively constant, increasing by several orders of magnitude in late-stage disease. Here, we develop and validate a theoretical model that altered lymphocyte circulation patterns between the lymph system and blood due to HIV-induced enhanced lymph-node homing and subsequent apoptosis of resting $\mathrm{CD}^{+}{ }^{+} \mathrm{T}$ cells can explain many aspects of HIV-1 disease progression. These results lead to a recalculation of the $\mathrm{CD} 4^{+}$lymphocyte dynamics during highly active antiretroviral therapy, and also suggest new targets for therapy. Key Words: HIV_Lymphocytes-Homing —Apoptosis-Mathematical model.
\end{abstract}

The mechanism by which HIV causes depletion of $\mathrm{CD} 4^{+}$lymphocytes in infected individuals remains unclear, and even the extent of $\mathrm{CD} 4^{+} \mathrm{T}$-cell elimination per unit of time is controversial. Several theories have been posited to explain this process (1-6). Any theory or model should reconcile the following hallmarks of the disease process.

Net loss of blood $\mathrm{CD}^{+}$lymphocytes is gradual and takes, on average, 10 years.

$\mathrm{CD}^{+} \mathrm{T}$-cell counts decrease proportionally in the blood much earlier than in lymph nodes, and in the early asymptomatic stages when most $\mathrm{CD}^{+}$lymphocytes are declining in the blood, their numbers concomitantly and transiently increase in the lymph nodes (lymphadenopathy) $(7,8)$.

Address correspondence and reprint requests to Denise Kirschner Department of Microbiology and Immunology, The University of Michigan Medical School, Ann Arbor, MI 48109-0620, U.S.A.; email: kirschne@umich.edu.

Manuscript received February 2, 2000; accepted April 24, 2000.
Compartmentalization of HIV-infected cells to lymphatic tissues occurs within which the preponderance of virus-producing cells reside, together with most of the virus in the body (trapped on follicular dendritic cells [FDCs]) $(9,10)$.

The number of productively-infected cells at any time is very low, in a ratio to uninfected cells at $1: 10^{5}$ (with approximately $10^{7}$ productively infected cells present in the whole body from a total of $10^{12}$ lymphocytes) $(9,11)$.

The $\mathrm{CD}^{+}$lymphocytes that die do so in lymph nodes, not in the blood, and most that die are bystander cells (i.e., not producing virus) (12-17).

Our work focuses on lymphocyte dynamics during HIV-1 infection. The factors determining this can be classified into three main areas: changes in cell production, changes in cell life-spans, and changes in cell migration patterns. Addressing the first hallmark given, namely the decline of $\mathrm{CD}^{+}$lymphocytes in the blood during HIV infection, three possible mechanisms for their loss exist: new $\mathrm{CD}^{+}$lymphocytes are not being 
generated at or above their normal rate; $\mathrm{CD} 4^{+} \mathrm{T}$ cells are being killed in the blood and cleared (whether by virus or cytotoxic T lymphocytes [CTLs] is not clear); or circulation patterns of $\mathrm{CD} 4^{+} \mathrm{T}$ cells in the blood are altered by increased homing out of blood into tissues.

Solid data support the first and last of these hypotheses, namely that loss of $\mathrm{CD} 4^{+}$lymphocytes in the blood may be due to both retarded production of $\mathrm{CD} 4^{+} \mathrm{T}$ cells and altered circulation patterns together with aberrant signaling leading to the induction of apoptosis. Data confirming these were recently published demonstrating that after 6 months of highly active antiretroviral therapy (HAART) there was an increase in new, naive $\mathrm{CD}^{+} \mathrm{T}$ cells (18), whereas the early return of $\mathrm{CD}^{+} \mathrm{T}$ cells following HAART appears to be due to redistribution (19). Furthermore, abortive HIV infection of resting lymphocytes leads to their upregulation of L-selectin (CD62L), the receptor on lymphocytes that is involved in homing to lymph nodes, and these cells displayed strong lymphnode homing properties $(20,21)$. These cells demonstrated an approximately 12 -fold increase in the ability to bind to high endothelial venules on frozen sections of lymph nodes, and when injected into the blood of mice infected with severe combined immunodeficiency syndrome (SCID), approximately $70 \%$ homed from the blood compartment into lymph nodes within 2 hours $(20,21)$. Further studies have shown that a large proportion (roughly half) of the cells that are induced to home through HIV binding, undergo apoptosis after they enter the lymph node (21). This results from secondary signaling of these cells through the homing receptors (CD62L, CD44, CD11a). These cells were shown to die without producing HIV. These cells that bind virus, but do not contain integrated viral DNA, are considered abortively infected. These cells fit the classical definition of abortive infection because virus binds and enters resting $\mathrm{CD}_{4}^{+}$cells and partially (or completely) reverse transcribes RNA into DNA, but the DNA does not integrate. Chun et al. (11) referred to these cells as preintegration latent; however, the classical definition of viral latency refers to a virus that can turn on and off its expression. Other studies have shown that classical latent infection occurs with HIV only after productive infection has occurred, and that these latently infected cells can be reactivated to productive infection.

Use of experimental models is relevant to corresponding processes occurring in humans. In two studies by Wang et al. $(20,21)$, signaling of resting $\mathrm{CD}^{+}$cells in culture was performed with HIV or, in the case of the homing receptors, with monoclonal antibody crosslinking or with their natural ligands. It is widely accepted that such signals mimic signaling of the same receptors in vivo. This is especially true when natural ligands are used in the in vitro studies. Those works also show that signaling through the homing receptors of HIV-bound cells induces many of them to die, whereas signaling of the homing receptors of normal lymphocytes does not. Presumably, this reflects what occurs in HIV-infected patients. Confirming the in vitro results, these same studies also show that "HIV-signalled" resting human $\mathrm{CD}^{+}{ }^{+}$ cells placed into the blood of SCID mice home at enhanced rates to the lymph nodes, and a large number die after entering the lymph node. SCID mouse studies of lymphocyte trafficking are considered relevant to normal homing processes, as homing receptors and homing processes are conserved among mammals. To show that these processes do actually occur in HIV-infected patients, in vivo studies have been performed that have been submitted soon for publication. These studies demonstrate that $\mathrm{CD}^{+}$lymphocytes in HIV-infected patients home to lymph nodes 2-3 times faster than $\mathrm{CD} 4^{+}$lymphocytes in uninfected individuals. Thus, in vitro and SCID mouse studies of Wang et al. $(20,21)$ have now been confirmed in patients.

These cited studies $(20,21)$ indicate that apoptosis occurs in HIV-signaled cells because of induction of Fas ligand following signals through homing receptors. Such signals normally occur on all cells homing into lymph nodes. Cloyd's unpublished data indicate that signaling through various homing receptors including L-selectin, integrins, or CD44, all induce upregulation of Fas ligand. Normally, naive or memory resting cells that are homing do not express Fas, and therefore induction of Fas ligand does not lead to apoptosis. What is abnormal with HIVsignaled cells is that they have upregulated Fas expression and thus homing can lead to apoptosis.

This enhanced homing and increased susceptibility to apoptosis may explain the bystander-cell effect that has been observed in lymph nodes of patients (12-17). These ideas are also supported by histologic studies showing that CD4:CD8 ratios do not change in lymph nodes coincident with changes in the blood ratios $(7,22,23)$. In addition, enhanced homing supports the observation that in the early stages of HIV infection, the numbers of $\mathrm{CD}^{+}$lymphocytes often increase in the lymph nodes (lymphadenopathy) with a concomitant decrease in blood $(7,24)$.

We therefore test the hypothesis that the decline in $\mathrm{CD}^{+}{ }^{+} \mathrm{T}$-cell counts in blood is due to altered lymphocyte circulation patterns resulting from HIV-induced homing of $\mathrm{CD}^{+} \mathrm{T}$ cells to lymph system, most of which are resting cells. One premise of this discussion is that the lymph system (LS) and blood do not operate in parallel as previously thought $(6,22)$, but rather, although the 
blood viral load grows, the LS viral load saturates early in infection. Using this hypothesis as a new premise explaining the disappearance of $\mathrm{CD}^{+}$lymphocytes from the blood, a model for the dynamics of lymphocyte turnover can be developed. Figure 1 diagrams these processes and is explained as follows. The model, validated against data, is used to generate new calculations on $\mathrm{CD} 4^{+}$lymphocyte dynamics during HAART.

HIV is produced primarily in the lymph nodes, because this is where most lymphocytes, and hence productively infected cells, reside. Newly produced virions bind to surrounding $\mathrm{CD} 4^{+}$lymphocytes and follicular dendritic cells (FDCs); given that only $1 \%$ to $2 \%$ of lymphocytes are activated (25), most virions interact with resting lymphocytes. After FDCs have become saturated with virus, the newly formed virions presumably flow out to the blood. Recent evidence suggests that virus can be released from FDCs $(9,10)$, supporting this hypothesis. Many abortively infected $\mathrm{CD} 4^{+} \mathrm{T}$ cells recirculate back into the blood within 1 to 2 days through normal lymphatic circulation patterns. Abortively infected $\mathrm{T}$ lymphocytes then home into lymph nodes at an enhanced rate, thus accounting for the gradual disappearance of the $\mathrm{CD}^{+}$lymphocytes in the blood. A portion of the $\mathrm{CD} 4^{+} \mathrm{T}$ lymphocytes that survive may enter the cell cycle if signaled within a short time frame, at which point they can produce virus. Thus, as more of these cells home into lymph nodes, greater numbers of productively infected cells result, and HIV levels in the body continue to rise. This in turn induces a cyclic pattern whereby constant, or increasing, numbers of $\mathrm{CD}^{+}$lymphocytes home from the blood into lymph nodes, a portion of which die during homing (Fig. 1).

\section{MODEL DEVELOPMENT}

\section{Lymphocyte Circulation}

We first describe normal lymphocyte circulation between the blood and lymph system in a healthy individual (26). There is unidirectional continuous flow of lymphocytes between blood and the LS. T cells in blood normally flow into the LS through a precisely controlled process (homing) and then, through the thoracic duct at the superior vena cava, they flow back into the blood. Classical experiments on lymphocyte circulation indicate that when the thoracic duct is cannulated and cells are not allowed to recirculate, the lymph nodes deplete of lymphocytes within 2 days (27-30). These studies indicate that lymphocytes cycle through this system approximately once daily $(23,27,31,32)$. Thus, inasmuch as only $2 \%$ of all lymphocytes are in the blood at any time, the average transit time through the blood must then be ap-

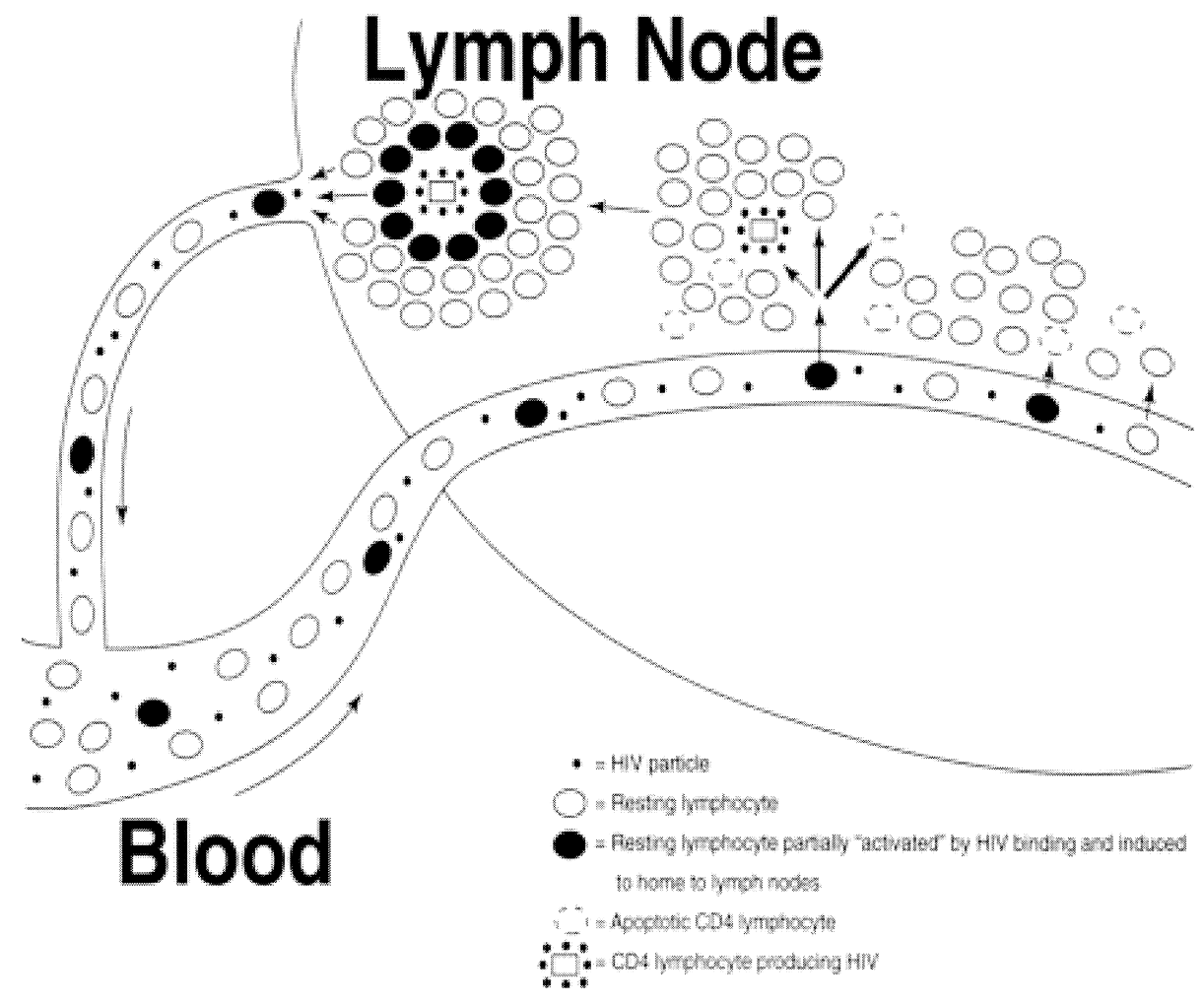

FIG. 1. Virus-lymphocyte interactions and lymphocyte circulation in the blood and lymph nodes. 
proximately 30 minutes, with the remainder of the 1-day circulation time being spent within the LS.

Patterns of cell trafficking during HIV infection are altered. In HIV-infected patients, normal trafficking of naive $\mathrm{CD}^{+}$lymphocytes and L-selectin-high memory cells (none of which have come in contact with HIV) migrate from the blood into lymph nodes and lymphoid tissues and if they do not encounter antigen, migrate back into the blood within a day or two, as in uninfected individuals. The time spent in the blood is approximately 30 minutes. However, any resting $\mathrm{CD}^{+}$lymphocyte in the lymph nodes that comes in contact with HIVproducing cells, free virions, or HIV-coated follicular dendritic cells can be signaled by HIV gp120 through its $\mathrm{CD} 4^{+}$receptor and upregulation of expression of homing receptors is thus induced. This increased expression of L-selectin maximizes at 36 to 40 hours after contact, at which time most of these resting cells will have migrated into the blood stream $(20,21$ and unpublished data). These cells then home back into the lymph nodes at enhanced rates, and during homing may receive secondary signaling that can induce approximately half (or more) of the cells into apoptosis.

To model this complex system of HIV-lymphocyte interactions mathematically, it is necessary to consider a two-compartment model including both blood and LS. Our goal is to explain the progression of HIV disease

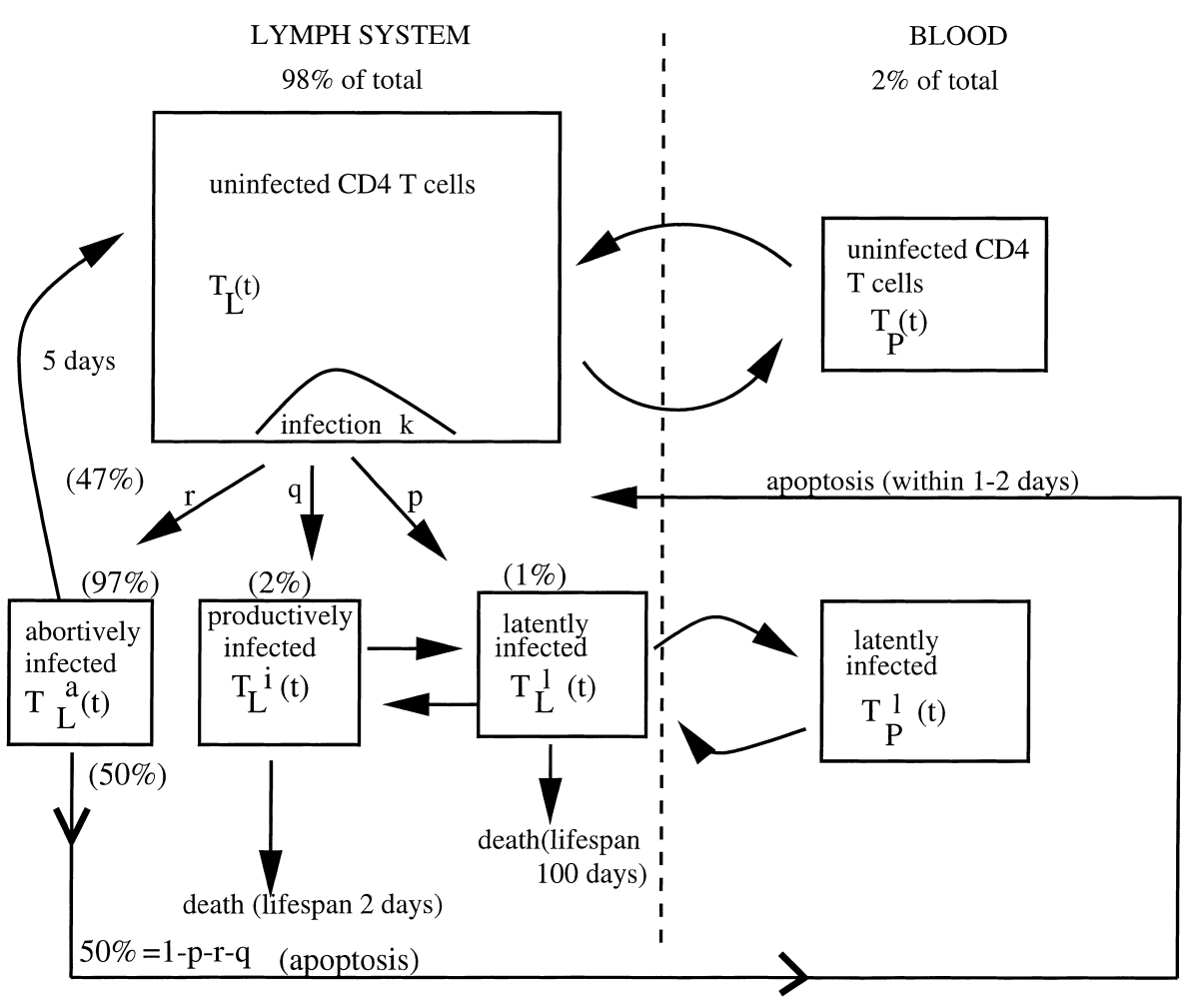

based directly on the effects HIV has on $\mathrm{CD} 4^{+} \mathrm{T}^{-}$-ell dynamics but only indirectly on the viral dynamics themselves. A more detailed model is forthcoming from our group that also examines viral dynamics. We consider the simplest interactions in each of the two compartments, blood and LS, as suggested by the diagram in Figure 2.

\section{Model Equations}

To model the cell population dynamics within each of these two compartments, we first divide the total population of $\mathrm{CD}^{+} \mathrm{T}$ cells into those in the blood and those in the LS. We define two populations in the blood: $T_{p}(t)$, the total number of uninfected $\mathrm{CD} 4^{+} \mathrm{T}$ cells in the blood, and $T_{P}^{l}(t)$, the total number of latently infected $\mathrm{CD}^{+} \mathrm{T}$ cells in the blood. These latently infected cells differ from abortively infected cells in that the viral DNA has been integrated into the host genome and, if these latent cells become activated by antigen presentation and enter the cell cycle, they can produce virus. We define four populations in the lymph system each measured in total number of cells: $T_{L}(t)$, the uninfected $\mathrm{CD} 4^{+} \mathrm{T}$ cells, $T_{L}^{a}(t)$, the abortively infected cells, $T_{L}^{l}(t)$, the latently infected cells, and $T_{L}^{l}(t)$ the activated, productively-infected cells.

FIG. 2. A two-compartmental model of the dynamics of $\mathrm{CD}^{+} \mathrm{T}$ cells during HIV-1 infection. 
Some key assumptions for the models are as follows. First, experimental evidence indicates that the immune system has the capacity to sense and respond to a reduced level in the total $\mathrm{CD}^{+} \mathrm{T}$-cell population, but not to reduced levels of the specific CD4 ${ }^{+} \mathrm{T}$-cell subset $(33,34)$. We assume that the rate of production and the rate of loss of uninfected $\mathrm{CD} 4^{+} \mathrm{T}$ cells is maintained in equilibrium. Thus, in the model, no source terms or loss terms exist for $\mathrm{CD} 4^{+} \mathrm{T}$-cell populations, except the small loss due to HIV infection (including abortive, latent, and productive infection). Therefore, the model could account for a lessthan-normal, normal, or more-than-normal cell turnover. This simplification also implies, however, that lymphadenopathy will not be observed in our model. Future models will be more comprehensive.

Second, based on normal lymphocyte circulation patterns, we assume uninfected and latently infected $\mathrm{T}$ cells spend 1 day in the LS and 0.5 hours in the blood $(27,28)$. Abortively infected cells home to the LS at an enhanced rate, where as many as 50\% are induced into apoptosis and the rest revert to the uninfected class after several days and rejoin normal circulation (21). This follows given that unintegrated viral DNA has a short half-life (35).

Third, we assume that most productively infected cells are in the LS; and that, because their lifespan is short, few circulate out to blood. Thus, we do not monitor the productively infected population nor the abortively infected cells in the blood. Because $>99 \%$ of the virusproducing cells are in the LS, nearly all estimated $10^{9}-$ $10^{10}$ virions $(6,36)$ produced per day must therefore be made in the LS. Consequently, most infection takes place in the LS.
The model equations are:

$$
\begin{aligned}
\frac{d T_{P}}{d t}= & c_{L} T_{L}(t)-c_{P} T_{P}(t), \\
\frac{d T_{P}^{l}}{d t}= & c_{L} T_{L}^{l}(t)-c_{P} T_{P}^{l}(t), \\
\frac{d T_{L}}{d t}= & c_{P} T_{P}(t)-c_{L} T_{L}(t)-k T_{L}(t)+\mu_{a} T_{L}^{a}(t), \\
\frac{d T_{L}^{l}}{d t}= & p k T_{L}(t)-c_{L} T_{L}^{l}(t)+c_{P} T_{P}^{l}(t)-\mu_{l} T_{L}^{l}(t) \\
& -s_{l} T_{L}^{l}(t)+s_{i} T_{L}^{i}(t), \\
\frac{d T_{L}^{a}}{d t}= & r k T_{L}(t)-\mu_{a} T_{L}^{a}(t), \\
\frac{d T_{L}^{i}}{d t}= & q k T_{L}(t)-\mu_{i} T_{L}^{i}(t)+s_{l} T_{L}^{l}(t)-s_{i} T_{L}^{i}(t),
\end{aligned}
$$

The viral-immune interactions outlined in Equations 1 through 6 are explained as follows. Equation 1 tracks the change in the uninfected, blood $\mathrm{CD} 4^{+} \mathrm{T}$-cell population. Because only a small fraction of lymphocytes are present in blood at any given time, the source and loss of cells from this compartment are reflected solely through lymphoid compartmental recirculation patterns. The first term is the source of cells from the LS, and the second

\begin{tabular}{|c|c|c|c|}
\hline & Definition & Value [reference] & Units \\
\hline \multicolumn{4}{|c|}{ Initial size } \\
\hline$T_{P}(0)$ & Uninfected blood $\mathrm{CD}^{+} \mathrm{T}$ cells & $2 \%$ of $T_{L}(0)$ & /total blood \\
\hline$T_{L}(0)$ & Uninfected lymph $\mathrm{CD}^{+}{ }^{+} \mathrm{T}$ cells & $2.0 \times 10^{11}(50)$ & /total lymph \\
\hline$T_{\mathrm{L}}^{l}(0)$ & Latently infected $\mathrm{T}$ cells & 0.0 & /total lymph \\
\hline$T_{L}^{a}(0)$ & Abortively infected $\mathrm{T}$ cells & 0.0 & /total lymph \\
\hline$T_{L}^{i}(0)$ & Actively infected $\mathrm{T}$ cells & 0.0 & /total lymph \\
\hline \multicolumn{4}{|c|}{ Parameters } \\
\hline$c_{L}$ & Circulation rate of cells out of LS into blood & $1.0(27-30)$ & /day \\
\hline$c_{P}$ & Circulation rate of cells out of blood into lymph system & $50.0(27-30)$ & /day \\
\hline$k$ & Infection rate of $\mathrm{CD} 4^{+} \mathrm{T}$ cells by virus & 0.001 & /day \\
\hline$p$ & Proportion of infected cells that are latently infected & $0.01(11)$ & scalar \\
\hline$q$ & Proportion of infected cells that are activated & $0.02(25)$ & scalar \\
\hline$s_{l}$ & Rate latently infected cells activate & 0.03 & /day \\
\hline$s_{i}$ & Rate actively infected cells shut down & 0.01 & /day \\
\hline$\mu_{a}$ & Conversion of abortively infected $\mathrm{T}$ cells & $0.2(35)$ & /day \\
\hline$\mu_{i}$ & Death rate of productively infected $\mathrm{T}$ cells & $0.5(36)$ & /day \\
\hline$\mu_{l}$ & Death rate of latently infected $\mathrm{T}$ cells & $0.01(51)$ & /day \\
\hline
\end{tabular}
term is the loss of cells from the blood as they circulate into the lymph system. Equation 2 represents the change in the population of latently infected cells in the blood. Latently infected cells circulate in fashion similar to that of the uninfected cells between blood and lymph, hence

TABLE 1. Parameter values with corresponding references in parentheses 
there are gain and loss terms representing exchange terms that are opposite in sign to those in Equation 4. Equation 3 monitors the change in the $\mathrm{CD}^{+} \mathrm{T}$-cell population in the lymph system. The first two terms are the same, but opposite in sign, to those in Equation 1 for blood $\mathrm{T}$ cells. This reflects the equivalent exchange of cells between compartments resulting from circulation. The third term reflects a loss of cells in the uninfected class due to infection, at rate $k$. Because we do not model the viral dynamics directly, we approximate this infection rate as a daily percentage of the $\mathrm{CD}^{+} \mathrm{T}$-cell population. The final term of Equation 3 is a gain term, at rate $\mu_{a}$, of abortively infected cells that, after several days, regain uninfected status when the unintegrated, unstable viral DNA degrades (35).

The source terms for the infected-cell equations each are a proportion of the infection process in Equation 3, namely $-k T_{L}(t)$. We assume that infection of cells is divided into four classes. The first, a proportion $p$, are latent infections (the first term of Equation 4). The second, a proportion $q$, are actively infected (the first term in Equation 6). The remainder comprises abortive infections and a proportion $r$ reverts to the uninfected state after $1 / \mu_{a}$ days, and $(1-p-r-q)$ home to lymph nodes and undergo apoptosis within 1 to 2 days $(20,21)$. Equation 5 marks the change in the abortively infected T-cell population. The first term is the gain due to infection, and the second term reflects the loss due to either conversion back to the uninfected state and includes the loss of cells due to apoptosis. Finally, Equation 6 represents the change in the productively infected T-cell population in the LS. The first term is the source due to infection, followed by a short life-span loss term. The last terms represent an exchange from the activation state either to, or from, the latent state in opposite sign to Equation 4.

\section{Parameter Estimates}

To present a mathematical model accurately, we must also estimate parameter values and initial population starting points for the rate constants and cell populations in the model. These parameters are the rate constants of the processes outlined in Equations 1 through 6. We note that the infected populations begin at 0 , given that we initiate the model at the inoculum. We also note that the model is robust for small changes in these parameter values, and these small changes would not qualitatively affect the model outcomes. A summary of the parameters and their values is presented in Table 1.

\section{MODEL VALIDATION AND PREDICTIONS}

The key purpose of developing a mathematical model to describe the lymphocyte-pathogen interactions we have outlined is to test whether these hypotheses can yield the disease observations and thus lend insight into the pathogenic mechanisms of HIV. We can then use the model to test theories associated with our hypotheses, such as turnover rates and the like. To this end, we solve the model system; the results are given in Figure 3. Behavior in both the blood and lymph compartment over an average of 7 years is consistent with experimental and clinical data for HIV-infected patients during the same time period $(11,20,21,33,34,37)$. Panel $A$ of Figure 3 presents data from three clinical studies representing the typical progression of T-cell loss in the blood during HIV infection, with the results of the model (solid line) given for direct comparison $(33,34,37)$.

Table 2 presents the comparison of the model simulation with proportional data for each class of infected cells; namely, the productively infected (active and producing virus), latently infected (provirus), and abortively infected $\mathrm{CD}^{+} \mathrm{T}$ cells in blood and the lymph system. Again, the model is consistent with experimental data (11). In the simulation, the overall rate of $\mathrm{CD} 4^{+} \mathrm{T}$-cell depletion in the blood is approximately $10^{6}$ per day (not shown). This corresponds to calculations made from values reported by Wolthers et al. (38).

\section{Apoptosis of Abortively Infected Cells}

Depletion of $\mathrm{CD}^{+}$lymphocytes in the LS during progression is due primarily to apoptosis of abortively infected cells. The effect of this loss can be gauged by a sensitivity analysis of the parameter $r$, corresponding to the survival fraction of abortively infected cells. As seen in Figure $3 B$, the population of uninfected $\mathrm{CD} 4^{+}$lymphocytes in the LS falls to approximately $15 \%$ of normal over a 10-year progression. The rate of decline depends on the value of $r$, as seen in Figure 4. As the survival fraction $r$ increases to its maximum possible value, the population of uninfected $\mathrm{CD}^{+}$lymphocytes in the LS falls to approximately $90 \%$ of normal during a 10 -year progression. The model is thus consistent with an explanation of $\mathrm{CD}^{+}$lymphocyte depletion in the LS during progression as a result of the loss of abortively infected cells, and not as a result of an impairment of the source of uninfected cells.

\section{$\mathrm{CD4}^{+}$Lymphocyte Dynamics During Highly Active Antiretroviral Therapy}

Previously published estimates of numbers of $\mathrm{CD}^{+}$ lymphocytes that turn over per day were based on the daily rates of $\mathrm{CD}^{+}$lymphocyte return to the blood following HAART $(5,39)$. The assumption was made that 

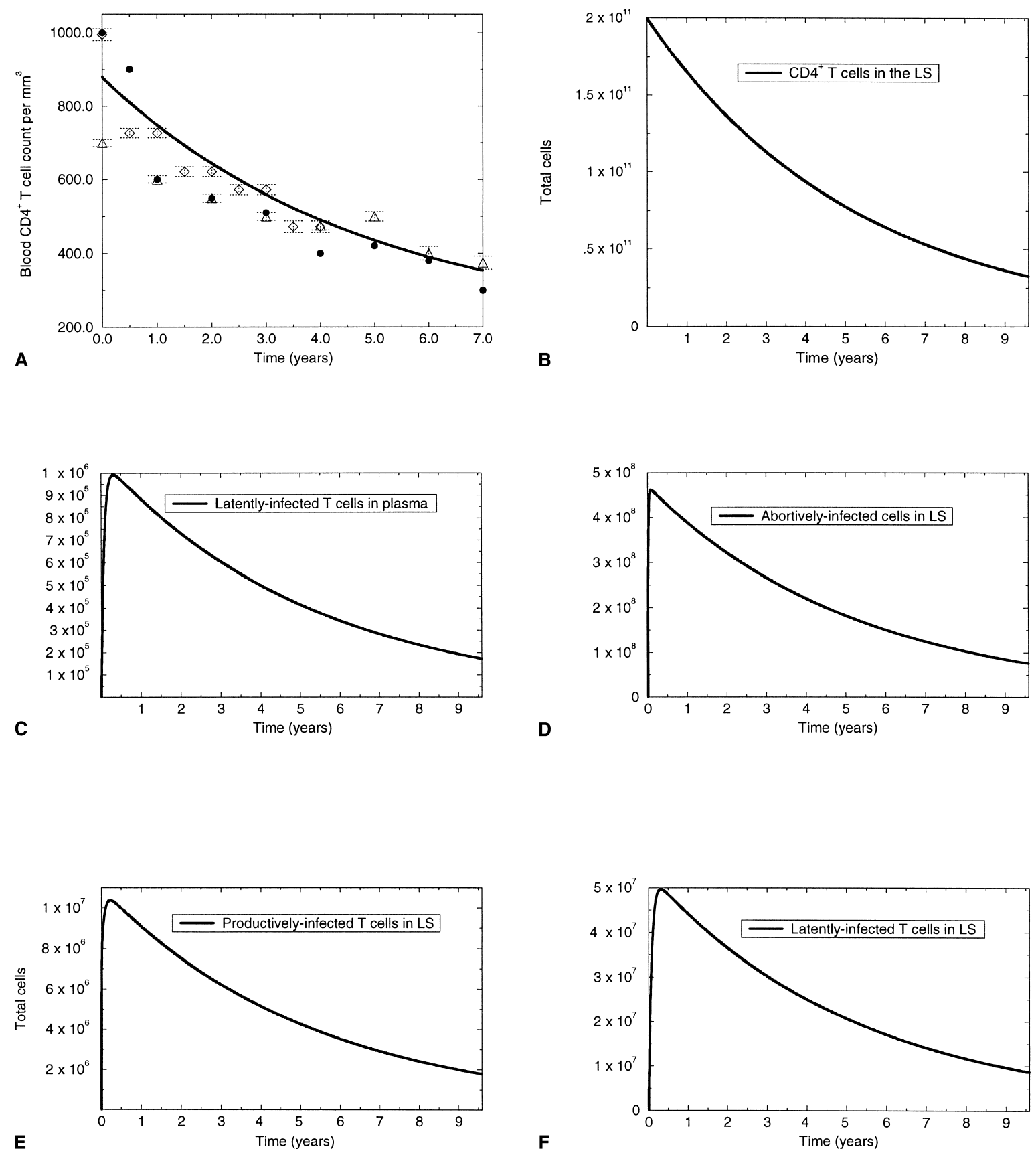

FIG. 3. Model solutions for both blood (A) and lymph (B) compartments (solid curves). Data showing the average time series of CD4 ${ }^{+}$ T-cell loss in blood during HIV-1 infection from three studies (37), $\diamond$ (33), and $\Delta$ (34). The model results are presented for direct comparison with peripheral data. (C-F) are the time courses for the latently infected cells in the blood (TPL), and the latently infected, actively infected and abortively infected cells in the lymph node, respectively. See Table 2 for comparison with other known ratios. Note that no time series of the kind shown in (A) is available for the LS cell dynamics.

the returning cells represent those that would be killed without therapy. Of course, in the small sample size, some individuals had a rate of return that was extremely small whereas in other patients it was more significant.
Both of these studies $(5,39)$, indicated that between 5 and 8 cells $/ \mathrm{mm}^{3}$ per day were returning in study subjects with a good response rate, giving a total of approximately $3 \times$ $10^{7} \mathrm{CD}^{+}$lymphocytes returning per day in the total $5 \mathrm{~L}$ 
TABLE 2. Model simulation values compared with data from Chun et al. (11)

\begin{tabular}{lll}
\hline \multicolumn{1}{c}{$\begin{array}{c}\text { Proportion of infected } \\
\text { cells by type }\end{array}$} & Model value & $\begin{array}{c}\text { Data from } \\
\text { Chun et al. }\end{array}$ \\
\hline $\begin{array}{l}\text { Productively infected } \\
\text { cells in lymph system }\end{array}$ & $T_{L}^{i} / T_{L}=0.01 \%$ & $0.02 \%$ \\
$\begin{array}{c}\text { Latently infected cells } \\
\text { in lymph system }\end{array}$ & $T_{L}^{l} / T_{L}=0.03 \%$ & $0.01 \%$ \\
$\begin{array}{l}\text { Abortively infected cells } \\
\text { in lymph system }\end{array}$ & $T_{L}^{a} / T_{\mathrm{L}}=0.3 \%$ & $0.5 \%$ \\
Latently infected cells in blood & $T_{P}^{l} / T_{P}=0.03 \%$ & $0.01 \%$ \\
\hline
\end{tabular}

blood. Even though these measurements were made under quasi-steady-state assumptions on the target cell population (implying that the results hold true for a short time scale) and that the lymphocytes in the blood reflect only $2 \%$ of the total body lymphocytes, the same loss rate was then extrapolated to the whole body, for the whole life-span of the infection. This led to the estimates of approximately $2 \times 10^{9}$ lymphocytes being destroyed per day in an HIV-infected person $(5,39)$.

These calculations done in studies by $\mathrm{Ho}$ et al. and Wei et al. $(5,39)$ were based on three hypotheses that had not been formally verified by data: disappearance of $\mathrm{CD} 4^{+}$lymphocytes in the blood is equated to their death; the number of $\mathrm{CD} 4^{+}$lymphocytes that return on therapy is equal to the number that normally die in an untreated individual; and changes in the numbers of $\mathrm{CD}^{+}$lymphocytes in the blood can be extrapolated to $\mathrm{CD}^{+}$lymphocytes throughout the body. Our theoretical model, together with our experimental data $(20,21)$, would suggest that these three hypotheses are incorrect. The phenomena observed can instead be explained as follows.

Disappearance of $\mathrm{CD}^{+}$lymphocytes in the blood is due to altered circulation properties and enhanced homing of cells and not to a high rate of cell turnover. Although our data indicate that at least half the cells that are abortively infected and induced to home to the LS are further induced into apoptosis inside the lymph nodes, our model also suggests that some survive and a small fraction of these will become virus-producing cells (21).

The CD $4^{+}$T-cell increase in the blood that occurs during HAART is due to termination both of HIV-induced homing and a return to normal circulation patterns as well as production of new cells $(18,19,40)$. This follows from the finding that in general, memory $\mathrm{T}$ cells, $\left(\mathrm{CD} 45 \mathrm{R0}^{+}\right)$, do not circulate through normal lymph node circulation patterns as naive cells $\left(\mathrm{CD}_{4}\right.$ RA $\left.\mathrm{RA}^{+}\right)$ do; however, our studies indicate that both naive and memory cells are induced by HIV-binding to home to lymph nodes (20). Thus, when HAART is adminis- tered, it is the memory cells that cease to home, and it is memory cells that have been shown disproportionately to return to blood after HAART (41). These cells would also have the greatest capacity to respond to antigen presentation and clonally expand.

The change in the numbers of $\mathrm{CD}^{+}$lymphocytes in the blood should not be extrapolated to the whole body, because enhanced homing will increase redistribution of $\mathrm{CD}^{+}$lymphocytes into the LS at the expense of the blood; and at least during infection, these compartments are not in parallel $(19,40)$. In addition, earlyinfection lymphadenopathy indicates that while lymphocytes are decreasing in the blood, they coincidentally rise in the lymph nodes.

In our model, simulation of HAART shows a small rebound to a steady state in which cells level off below their normal, uninfected levels (not shown). No rebound above this level is seen given that we do not include a source of new naive cells into the blood and LS. If we include this source of new cells, we can obtain rebounds as observed in studies by three separate groups led by Hellerstein, Bucy, and Pakker $(18,19,40)$.

\section{Recalculation of Cell Dynamics}

Using the three premises just stated, recalculation of the number of $\mathrm{CD}^{+}$lymphocytes that die per day can be made. First, from published data $(5,39)$ the numbers of cells that return on HAART range widely from $4 \times 10^{6}$ $-1.08 \times 10^{8}$ total per day in the blood. These values are inversely correlated to stage of infection, with the lower values corresponding to pre-AIDS blood $\mathrm{CD}^{+}{ }^{+} \mathrm{T}$-cell counts. In our model, a typical pre-AIDS count is approximately $500 / \mathrm{mm}^{3}$ at 3 years after infection, at which time the total number of abortively infected cells in the body is between $10^{8}-10^{9}$ cells and productively infected cells number approximately $10^{6}-10^{7}$ at any given time. Before HAART, the abortively infected cell compartment, $T_{L}^{a}(t)$ is in relative equilibrium. After HAART, the $T_{L}^{a}(t)$ compartment empties as the abortively infected cells revert to the compartment of uninfected cells in the LS, $T_{L}(t)$. These cells spend approximately $2 \%$ of their time in the blood compartment $T_{p}(t)$. Thus, $2 \times 10^{7}$ total cells appear in the blood after HAART, or about $4 \times$ $10^{6}$ day, which corresponds to the lower value given by Ho et al. (5). Release and altered circulation of abortively infected cells can therefore account for the observed increase of cells in the blood during HAART, at least before the onset of the final AIDS collapse of the $\mathrm{CD}^{+}$ T-cell population.

Because of the extremely high numbers of cells turn- 


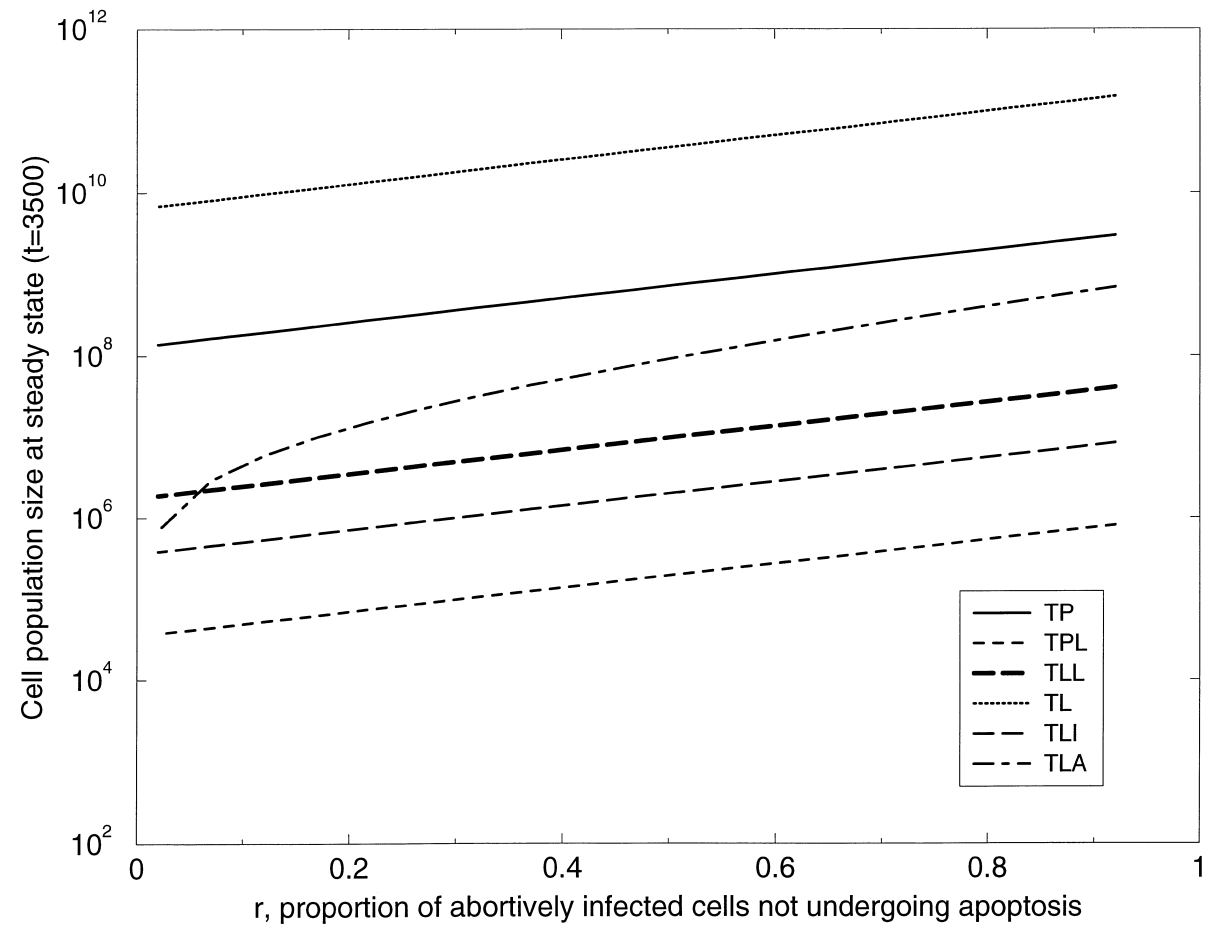

FIG. 4. Graphs of the values of the uninfected and infected $\mathrm{CD}^{+}$lymphocyte populations in the blood and lymph system after 10 years of disease progression as a function of the parameter $r$ (the proportion of abortively infected cells that do not undergo apoptosis). A typical progression (as seen in Fig. 3 with $r=0.5)$ corresponds to a depletion of $\mathrm{CD}^{+}$lymphocytes in the LS to approximately $15 \%$ of normal at 10 years. As $r$ increases to 1 , the population of uninfected $\mathrm{CD4}^{+}$lymphocytes in the lymph system at 10 years approaches approximately $90 \%$ of normal. ing over per day in the previous models $(5,39)$, the assumption had to be made that cell renewal occurs widely on a daily basis; otherwise a patient would advance to AIDS in a matter of weeks. With our model of disease progression, the assumption of an extremely high renewal of cells is not necessary. Instead, our model, which makes no assumptions about $\mathrm{CD}^{+}{ }^{+} \mathrm{T}$-cell renewal, assumes instead that there is a gradual net loss of a small number of cells daily due to infection that over a 10 -year time-span leads to eventual elimination of most $\mathrm{CD}^{+}$ lymphocytes in the blood. This idea is consistent with earlier and more recent studies $(18,41)$, which demonstrate that the half-life of $\mathrm{CD}^{+} \mathrm{T}$ cells in blood of late stage HIV-positive patients is about one-third normal and is not compensated by a major increase in the absolute production rate.

In addition, only a small fraction of virus-producing cells is needed to account for the estimated amounts of HIV produced per day $\left(10^{9}-10^{10}\right.$ virions) (36), given that one productively infected cell produces $10^{2}$ to $10^{3}$ virions/24 hours $(10,42,43)$. Thus, approximately $10^{7}$ productively infected cells out of $10^{12}$ total lymphocytes in the whole body should suffice to produce the observed amounts of virus.

\section{DISCUSSION}

Our mathematical modeling combined with experimental evidence $(20,21)$ supports the scheme presented in Figure 1 as a major mechanism of HIV pathogenesis. The effects of HIV (induction of lymph-node homing, and apoptosis after entering the lymph nodes) on resting $\mathrm{T}$ lymphocytes can explain the depletion of $\mathrm{CD}^{+} \mathrm{T}$ lymphocytes from the peripheral blood when few blood $\mathrm{CD}^{+}$lymphocytes are productively infected. It also can help explain end-stage depletion of $\mathrm{CD}^{+} \mathrm{T}$ lymphocytes from the lymph nodes. One consequence of viral induced homing is that it correlates directly with the amount of virus present in the LS. As the disease stage progresses, this viral load should increase, and hence even greater amounts of homing and apoptosis occur. Thus, this idea is consistent with late-stages of disease with low T-cell counts in the blood and high viral loads (which are produced in the lymph nodes).

This model of HIV disease also allows reexamination of the rates of cell production and turnover during infection. It lends insight into the dynamics seen during treatment with HAART, which is important for understanding the effects of chemotherapy. Given that latently infected cells are unaffected by therapy but do harbor provirus, and that these cells can later reactivate and reestablish infection; they can play a key role in the success or failure of treatment.

The thymus plays an important role in HIV-1 disease progression (44-47). It may serve as a source of both virus and infected cells, thus augmenting systemic infection (44). However, if the thymus retains its function during infection, it can then continue supplying lympho- 
cytes to the blood, potentially slowing disease progression (47). In our model, turnover of $\mathrm{CD}^{+} \mathrm{T}$ cells is in balance except for the loss due to HIV infection. If a compartment is added to the model to represent the thymus, then the progression to AIDS is augmented if the thymus is also a source of virus and infected cells; however, a functional thymus can slow the progression by supplying new lymphocytes to blood. Thus, our model is consistent with the known effects of the thymus in HIV pathogenesis $(45,46)$.

Moreover, other markers of disease progression exist in HIV aside from $\mathrm{CD} 4^{+} \mathrm{T}$-cell depletion that includes viral coreceptor usage, replication kinetics, immune response effects, and the like. However, we have simplified our model to study only the effects of enhanced homing. Certainly, a more complex model incorporating these other mechanisms would serve to refine the model further, because although we believe enhanced homing is a key mechanism of HIV pathogenesis, it does not operate alone. Future work will attempt to explore these combined issues.

The model generated by our mathematical description of these processes shows that this small loss would lead to a net decline of $\mathrm{CD} 4^{+}$lymphocytes of approximately 100 cells $/ \mathrm{mm}^{3} /$ year leading to the almost complete loss of $\mathrm{CD}^{+}$lymphocytes after 10 years. This model likely presents a more accurate picture because it is based on experimental data about what HIV does to resting lymphocytes (the majority), and this model can predict key hallmark features of HIV infection. Others have also hypothesized that an imbalance in homeostasis as well as cell redistribution may be responsible for HIV dynamics supporting our theory (48).

As treatment strategies for HIV infection encounter increasing problems due to both the development of drug resistance and residual replication in latent cells $(49,50)$, new approaches are urgently needed. Therapeutic approaches involving inhibition of viral-induced homing and/or homing-induced apoptosis, in conjunction with treatments that inhibit viral replication, may prove beneficial for HIV-infected study subjects.

Acknowledgments: We wish to thank Powel Kazanjian, and Sally M. Blower, and Victor DiRita for helpful discussions and reading of the manuscript. This work was partially funded by the National Institutes of Health (grant R01-HL62119-01 to D.K.), National Science Foundation (grant 9805515 to G.F.W.), and National Institutes of Health (grant R01-AI43244 and AmFAR to M.C.).

\section{REFERENCES}

1. Nowak MA, May RM, Anderson RM. The evolutionary dynamics of HIV-1 quasispecies and the development of immunodeficiency disease. AIDS 1990;4:1095-1103.
2. Nowak MA, May RM. Mathematical biology of HIV infections: antigenic variation and diversity threshold. Math Biosci 1991;106: $1-21$.

3. Wodarz D, Klenerman P, Nowak MA. Dynamics of cytotoxic Tlymphocyte exhaustion. Proc Roy Soc Lond B 1998;265:191-203.

4. Wodarz D, Lloyd AI, Jansen VAA, Nowak MA. Dynamics of macrophage and T cell infection by HIV. J Theor Biol 1999;196: $101-13$.

5. Ho DD, Neumann AU, Perelson AS, et al. Rapid turnover of plasma virions and CD4 lymphocytes in HIV1 infection. Nature 1995;373:123-6.

6. Ho DD. Viral counts in HIV infection. Science 1996;272:1124-5.

7. Janossy G, Pinching JA, et al. An immunohistological approach to persistent lymphadenopathy and its relevance to AIDS. Clin Exp Immunol 1985;59:257-69.

8. Mangkornkanok-Mark M, Mark AS, et al. Immunoperoxidase evaluation of lymph nodes from acquired immune deficiency patients. Clin Exp Immunol 1984;55:581-6.

9. Embretson J, Zupancic M, Ribas JL, et al. Massive covert infection of helper T lymphocytes and macrophages by HIV during the incubation period of AIDS. Nature 1993;362:359-62.

10. Haase AT, Henry K, Zupancic M, et al. Quantitative image analysis of HIV-1 infection in lymphoid tissue. Science 1996;274: 985-9.

11. Chun TW, Carruth L, Finzi D, Shen X, et al. Quantification of latent reservoirs and total body viral load in HIV-1 infection. $\mathrm{Na}$ ture 1997;387:183-7.

12. Finkel TH, Tudor-Williams G, et al. Apoptosis occurs predominantly in bystander cells and not in productively infected cells of HIV- and SIV-infected lymph nodes. Nat Med 1995;1:129-35.

13. Conti L, Rainaldi G, Matarrese P, et al. The HIV-1 vpr protein acts as a negative regulator of apoptosis in human lymphoblastoid $\mathrm{T}$ cell lines: implications for the pathogenesis of AIDS. J Exp Med 1998;187:403-13.

14. Kameoka M, Suzuki S, Kimura T, et al. Exposure of resting peripheral blood T cells to HIV-1 particles generates CD25+ killer cells in a small subset, leading to induction of apoptosis in bystander cells. Int Immunol 1997;9:1453-62.

15. Carbonari M, Pesce AM, Cibati M, et al. Death of bystanders cells by a novel pathway involving early mitochondrial damage in HIVrelated lymphadenopathy. Blood 1997;90:209-16.

16. Leno M, Hague BF, Teller R, Kindt TJ. HIV-1 mediates rapid apoptosis of lymphocytes from CD4 transgenic but not normal rabbits. Virology 1995;213:450-4.

17. Finkel TH, Banda NK. Indirect mechanisms of HIV pathogenesis: how does HIV kill cells? Curr Opin Immunol 1994;6:605-15.

18. Hellerstein M, Hanley MB, Cesar D, Siler S, et al. Directly measured kinetics of circulating T lymphocytes in normal and HIV-1 infected humans. Nat Med 1999;5:83-9.

19. Bucy RP, Hockett RD, Derdeyn CA, et al. Initial increase in blood cd4(+) lymphocytes after HIV antiretroviral therapy reflects redistribution from lymphoid tissues. J Clin Invest 1999;103:1391-8.

20. Wang L, Robb CW, Cloyd MW. HIV induces homing of resting T lymphocytes to lymph nodes. Virology 1997;228:141-50.

21. Wang L, Chen B, Gelman JY, Konig R, Cloyd MW. Mechanism of CD4 lymphocyte depletion involves HIV's effects on resting lymphocytes: induction of lymph node homing and apoptosis upon secondary signaling through homing receptors. J Immunol 1999; 162:268-76.

22. Rosok BI, Bostad L, Voltersvik P, et al. Reduced cd 4 cell counts in blood do not reflect cd4 depletion in tonsillar tissue in asymptomatic HIV-1 infection. AIDS 1999;10:F35-8.

23. Mackay CR, Marston W, Dudler L. Altered patterns of T cell migration through lymph nodes and skin following antigen challenge. Eur J Immunol 1992;22:2205-10.

24. Rosenberg YJ, Zack PM, et al. Decline in the CD4+ lymphocyte population in the blood of SIV-infected macaques is not reflected in lymph nodes. AIDS Res Hum Retroviruses 1993;9:639-48.

25. Janeway CA, Travers P. Immunobiology: the immune system in 
health and disease. New York: Current Biology Ltd./Garland Publishing, 1996.

26. Stekel DJ, Parker CE, Nowak MA. A model of lymphocyte circulation. Immunol Today 1997;18:216-21.

27. Sprent J. Circulating T and B lymphocytes of the mouse: migratory properties. Cell Immunol 1973;7:10-39.

28. Sprent J, Basten A. Circulating T and B lymphocytes of the mouse: lifespans. Cell Immunol 1973;7:40-59.

29. Westerman J, Pabst R. Lymphocyte subsets in the blood: a diagnostic window on the lymphoid system? Immunol Today 1990;11: 406-10.

30. Pabst R. The spleen in lymphocyte migration. Immunol Today 1988;9:43-5.

31. Ford WL, Gowans JL. The traffic of lymphocytes. Semin Hematol 1969;6:67-80.

32. Smith ME, Ford WL. The recirculating lymphocyte pool of the rat: a systemic description of the migratory behavior of recirculating lymphocytes. Immunology 1969;49:83-100.

33. Margolick JB, Donnenberg AD, Munoz A, et al. Changes in T and non-T lymphocyte subsets following seroconversion to HIV-1. J Acquir Immune Defic Syndr 1993;6:153-61.

34. Margolick JB, Donnenberg AD, Munoz. T lymphocytes homeostasis after HIV seroconversion. J Acquir Immune Defic Syndr 1994;7:415-16.

35. Zack JA, Arrigo SJ, Weitsman SL, et al. HIV-1 entry into quiescent primary lymphocytes: molecular analysis reveals a labile, latent viral structure. Cell 1990;61:213-22.

36. Perelson AS, Neumann AU, Markowitz M, et al. HIV-1 dynamics in vivo: virion clearance rate infected cell life span and viral generation time. Science 1996;271:1582-6.

37. Pennisi E, Cohen J. Eradicating HIV from a patient: not just a dream? Science 1996;272:1884.

38. Wolthers KC, Bea G, Wisman A. T cell telomere length in HIV-1 infection: no evidence for increased CD4+ $\mathrm{t}$ cell turnover. Science 1996;274:1543-7.

39. Wei X, Ghosh SK, Taylor ME, et al. Viral dynamics in HIV virus 1 infection. Nature 1995;373:117-22.

40. Pakker NG, Notermans DW, DeBoer RJ, et al. Biphasic kinetics of peripheral blood T cells after triple combination therapy in HIV-1 infection: a composite of redistribution and proliferation. Nat Med 1998;4:208-13.

41. Hellerstein MK, McCune JM. T cell turnover in HIV-1 disease. Immunity 1997;7:583-9.

42. Levy JA. CD4+ cell counts, and HIV-1 production by cells [letter; comment]. Science 1996;271:670-1.

43. Tsai WP, Conley SR, Kung HF, Garrity RR, Nara PL. Preliminary in vitro growth cycle and transmission studies of HIV-1 in an autologous primary cell assay of blood-derived macrophages and peripheral blood mononuclear cells. Virology 1996;226:205-16.

44. Kirschner D, Mehr R, Perelson A. The role of the thymus in pediatric HIV-1 infection. J Acquir Immune Defic Syndr Hum Retrovirol 1998;18:95-109.

45. Kourtis A, Iberbu C, Nahmias AJ, et al. Early progression of disease in HIV-infected infants with thymus dysfunction. $N$ Engl $J$ Med 1996;335:1431-6.

46. Nahmias AJ, Clark WS, Kourtis AP, et al. Thymic dysfunction and time of infection predict mortality in HIV-infected infants. J Infect Dis 1998;178:680-5.

47. McCune JM, Loftus R, Schmidt DK, et al. High prevalence of thymic tissue in adults with HIV-1 infection. J Clin Invest 1998; 101:2301-8.

48. Grossman Z, Herberman RB. T cell homeostasis in HIV infection is neither failing nor blind: modified cell counts reflect and adaptive response of the host. Nat Med 1997;3:486-90.

49. Zhang L, Ramratnam B, Tenner-Racz K, et al. Quantifying residual HIV-1 replication in patients receiving combination and antiretroviral therapy. $N$ Engl J Med 1999;340:1605-13.

50. Furtado MR, Duncan S, Callaway BS, et al. Persistence of HIV-1 transcription in peripheral blood mononuclear cells in patients receiving potent antiretroviral therapy. N Engl J Med 1999;340: 1614-21.

51. Westermann J, Pabst R. Distribution of lymphocyte subsets and natural killer cells in the human body. Clin Invest 1992;70:539-44.

52. Tough DF, Sprent J. Lifespan of lymphocytes. Immunol Res 1995; 14:1-14. 